\title{
Antimicrobial Resistance Patterns of Aeromonas spp. Isolated from Orna- mental Fish
}

\author{
Carla Dias ${ }^{1,2}$, Vânia Mota ${ }^{1}$, António Martinez-Murcia ${ }^{4}$ and Maria José Saavedra ${ }^{1,3,5 *}$ \\ ${ }^{1}$ CECAV-University of Trás-os-Montes e Alto Douro, 5000- 801 Vila Real, Portugal \\ ${ }^{2}$ CITAB-University of Trás-os-Montes e Alto Douro, 5000- 801 Vila Real, Portugal \\ ${ }^{3}$ Department of Veterinary Sciences, School of Agriculture and Veterinary Science, University of Trás-os-Montes e Alto Douro, Vila Real, Portugal \\ ${ }^{4}$ Universidad Miguel Hernández, Orihuela E-03300, Alicante, Spain \\ ${ }^{5}$ CIMAR/CIIMAR - Centro Interdisciplinar de Investigação Marinha e Ambiental and ICBAS - Instituto
}

\begin{abstract}
The potential risk of occurrence of new diseases associated with the trade of live animals is well known. However little importance is still given to the problematic of the dissemination of resistance genes that pass along with the animal trade. In this study we aimed to isolate Aeromonas spp. strains from water and skin of ornamental fish and test their resistance to antibiotics. The samples were collected from a national ornamental fish importer, with the intent of obtaining a collection of Aeromonas strains. The identification of the strains was made by gyrB and $r p o D$ gene sequencing. A total of 288 strains grouped in seven different species - Aeromonas veronii, Aeromonas media, Aeromonas jandaei, Aeromonas hydrophila, Aeromonas caviae, Aeromonas culicicola, Aeromonas aquariorum, were isolated. The susceptibility profile was determined for 28 antibiotics commonly used. All the strains presented multi-resistance to the tested antibiotics. The antibiotic susceptibility profile to tetracycline, ticarcillin, carbenicillin ampicillin and erythromycin revealed resistance levels of more than $80 \%$. Few strains resistant to aztreonam and imipenem were identified. On the other hand, all were sensitive to cefotaxime and cefepime. The results show that these Aeromonas spp. strains are potentially reservoirs of antibiotic resistance genes.
\end{abstract}

Keywords: Aeromonas spp.; Antibiotic resistance; Ornamental fish

\section{Introduction}

Bacterial disease is one of the most important diseases in ornamental fishes and a significant cause of high fish morbidity and mortality rates [1]. Many stress factors could contribute to bacterial infection in ornamental fish, namely, poor water quality, crowding, transportation and inadequate nutrition [2].

The genus Aeromonas belongs to the family Aeromonadaceae within the Gammaproteobacteria and comprises Gram-negative, nonspore-forming, motile bacilli or coccobacilli rods with rounded ends which measure 1-3,5 $\mu \mathrm{m}$ across [3]. They are facultative anaerobic, oxidase, catalase and indol-positive, able to reduce nitrate to nitrite and are, glucose-fermenting, generally resistant to the vibriostatic agent $\mathrm{O} / 129$ $[4,5]$.

Members of the genus Aeromonas are found in a wide variety of ecological niches. They are able to inhabit surface water (rivers, lakes), sewage, drinking water (tap and bottled mineral), thermal water and sea water [6,7]. Some species, mainly the psychrophilic Aeromonas salmonicida and the mesophilic Aeromonas hydrophila and Aeromonas veronii are recognized causative agents of fish disease $[3,8]$.

Infections caused by motile aeromonads are probably the most common bacterial disease of freshwater fish [9]. Resistance of Aeromonas spp. to commonly used antibiotics is an emerging problem in the ornamental fish. An increase in resistance levels of the genus Aeromonas, particularly to $\beta$-lactam antibiotics has been observed previously $[10,11]$. Antimicrobial resistance genes, including cassette-borne resistance genes in class I integrons, have been described as occurring in $A$. salmonicida and in motile aeromonads [12-14].

The objective of the present study is to isolate and identify Aeromonas spp. from the water of aquarium and the skin of imported or- namental fish and to evaluate their susceptibility to some antimicrobial agents.

\section{Materials and Methods}

\section{Bacteria strains isolation and identification}

This evaluation was conducted with samples of skin and water (30 and 14 according to the fish and tanks available, respectively) from imported ornamental fish. Water samples filtered onto nitrocellulose membranes and from fish skin were collected aseptically and incubated at $30^{\circ} \mathrm{C}$ for $24 \mathrm{~h}$ on GSP media (Oxoid, Basingstoke, UK). This media was used to isolate (typical colonies, i.e. yellow on GSP medium) and purify the strains. Bacteria strains were identified, following standard procedures, to identify Aeromonas at the genus level, and further standard biochemical classification was performed by using API $50 \mathrm{CH}$ (bioMérieux) at $30^{\circ} \mathrm{C}$ for $48 \mathrm{~h}$, following the manufacturer's instructions. Procedures and characteristics of oligonucleotide primers for amplification and PCR-based sequencing house-keeping genes ( gyrB and $r p o D$ ) are as described previously [15]. PCR products were purified with QIAquick PCR purification kit (QIAGEN, Germany), following the manufacturer's instructions and prepared for sequencing by using the Big Dye Terminator V.3.1 cycle sequencing kit and amplified genes were sequenced with an ABI PRISM 3100 Genetic Analyser (Applied Biosystems, USA).

*Corresponding author: Maria José Saavedra, Department of Veterinary Sciences, School of Agriculture and Veterinary Science, University of Trás-os-Montes e Alto Douro, Vila Real, Portugal, E-mail: saavedra@utad.pt

Received March 27, 2012; Accepted April 26, 2012; Published May 05, 2012

Citation: Dias C, Mota V, Martinez-Murcia A, SaavedraMJ (2012) Antimicrobial Resistance Patterns of Aeromonas spp. Isolated from Ornamental Fish. J Aquacult Res Dev 3:131 doi:10.4172/2155-9546.1000131

Copyright: (C) 2012 Dias C, et al. This is an open-access article distributed unde the terms of the Creative Commons Attribution License, which permits unrestricted use, distribution, and reproduction in any medium, provided the original author and source are credited. 
Citation: Dias C, Mota V, Martinez-Murcia A, SaavedraMJ (2012) Antimicrobial Resistance Patterns of Aeromonas spp. Isolated from Ornamental Fish. J Aquacult Res Dev 3:131 doi:10.4172/2155-9546.1000131

\section{Antibiotic susceptibility testing}

Aeromonas spp. strains isolated in the present study were subjected to susceptibility testing against 28 antimicrobials commonly used. Susceptibility was determined by the disk-diffusion technique of KirbyBauer on Mueller-Hinton agar plates (Oxoid Basingstoke, UK) with inocula adjusted to an optical density of $0.5 \mathrm{McF}$ arland standard units [16]. Disks containing ampicillin $\left(\mathrm{AMP}_{10 \mu \mathrm{g}}\right)$, carbenicillin $(\mathrm{CAR} 100 \mu \mathrm{g})$, amoxicillin $\left(\mathrm{AML}_{10 \mathrm{ug}}\right)$, amoxicillin/ clavulanic acid $\left(\mathrm{AMC}_{30 \mathrm{gg}}\right)$, piperacillin $\left(\mathrm{PRL}_{100 \mu \mathrm{g}}\right)$, piperacillin/ tazobactam $\left(\mathrm{TZP}_{110 \mathrm{\mu g}}\right)$, ticarcillin $\left(\mathrm{TIC}_{75 \mu \mathrm{g}}\right)$, ticarcillin/ clavulanic acid $\left(\mathrm{TIM}_{85 \mu \mathrm{g}}\right)$, cephalothin $\left(\mathrm{KF}_{30 \mu \mathrm{\mu g}}\right)$, cefoxitin $\left(\mathrm{FOX}_{30 \mathrm{\mu g}}\right)$, cefotaxime $\left(\mathrm{CTX}_{30 \mathrm{\mu g}}\right)$, cefoperazone $\left(\mathrm{CFP}_{30 \mathrm{\mu g}}\right)$, ceftazidime $\left(\mathrm{CAZ}_{30 \mu \mathrm{g}}\right)$, ceftriaxone $\left(\mathrm{CRO}_{30 \mu \mathrm{g}}\right)$, cefepime $\left(\mathrm{FEP}_{30 \mathrm{\mu g}}\right)$, aztreonam $\left(\mathrm{ATM}_{30 \mathrm{\mu g}}\right)$, imipenem (IMP $\left.{ }_{10 \mathrm{\mu g}}\right)$, gentamicin $\left(\mathrm{CN}_{10 \mathrm{\mu g}}\right)$, kanamycin $\left(\mathrm{K}_{30 \mathrm{\mu g}}\right)$, tobramycin $\left(\mathrm{TOB}_{10 \mathrm{\mu g}}\right)$, amikacin $\left(\mathrm{AK}_{30 \mathrm{\mu g}}\right)$, netilmicin $\left(\mathrm{NET}_{30 \mathrm{\mu g}}\right)$, tetracycline $\left(\mathrm{TE}_{30 \mathrm{\mu g}}\right)$, ciprofloxacin $\left(\mathrm{CIP}_{5 \mu \mathrm{g}}\right)$, norfloxacin $\left(\mathrm{NOR}_{10 \mathrm{\mu g}}\right)$, erythromycin $\left(\mathrm{E}_{15 \mu \mathrm{g}}\right)$, trimethoprim/sulfamethoxazole $\left(\mathrm{SXT}_{25 \mu \mathrm{g}}\right)$ and chloramphenicol $\left(\mathrm{C}_{30 \mu \mathrm{g}}\right)$ were used. All disks were obtained from Oxoid. After $24 \mathrm{~h}$ incubation at $30^{\circ} \mathrm{C}$, organisms were classified as sensitive (S), intermediately resistant (I) or resistant (R) on the basis of the size of the zone of bacteria growth inhibition according to the guidelines of the CLSI (2010).

\section{Results and Discussion}

The genus Aeromonas has been the subject of various antimicrobial susceptibility studies over the last years. Although Aeromonas species are distributed throughout the world, there are geographic differences in the frequency of diseases caused by these bacteria [3].

A total number of 299 isolates were obtained from aquaria of ornamental fish shops (221 from skin and 77 from water). Using gyrB and rpoD sequencing several species of Aeromonas were identified, namely 110 Aeromonas veronii $(36,8 \%), 106$ Aeromonas hydrophila $(35,5 \%)$, 43 Aeromonas aquariorum (14, 4\%), 24 Aeromonas culicicola (8, 0\%), 3 Aeromonas media (1,0\%), one Aeromonas caviae (0,4\%), and one Aeromonas jandaei $(0,4 \%)$. A. hydrophila has been the most common bacteria associated with aquatic animal disease. In a Malaysian aquarium shop, $60 \%$ of $A$. hydrophila were isolated from sick freshwater ornamental fish [2]. Other reports also refer to the antimicrobial susceptibility of clinical isolates of this specie [17] and in a prevalence study of fish and prawn from south India market, $33.5 \%$ and $17.6 \%$ of $A$. hydrophila were isolated, respectively [18].

Strains of Aeromonas spp. $(\mathrm{n}=225)$ characterized genetically (43 Aeromonas aquariorum, 67 A. hydrophila, 94 A. veronii, 16 A. culicicola $3 \mathrm{~A}$. media, $1 \mathrm{~A}$. caviae and $1 \mathrm{~A}$. jandaei) were tested for susceptibility to a panel of 28 antibiotics. The results are presented in Table 1 (in percentage); however, the values regarding A. media, A. caviae and A. jandae are not included due to the small number of isolates found. Our results show the existence of differences in some of the antibiotics tested according to the species and a high incidence of resistance of Aeromonas isolates to $\beta$-lactams antibiotics, as $95 \%$ were resistant to amoxicillin, $96 \%$ to carbenicillin and $94 \%$ to ampicillin (Table 1). It is noteworthy, that the main differences were in the isolates of Aeromonas aquario-

\begin{tabular}{|c|c|c|c|c|c|c|c|c|c|c|c|c|c|}
\hline \multirow[t]{2}{*}{ Antibiotic } & \multicolumn{3}{|c|}{$\begin{array}{l}\text { A. aquariorum } \\
(\mathrm{n}=43)\end{array}$} & \multicolumn{3}{|c|}{$\begin{array}{l}\text { A. hydrophila } \\
(\mathrm{n}=67)\end{array}$} & \multicolumn{3}{|c|}{$\begin{array}{l}\text { A. veronii } \\
(\mathrm{n}=94)\end{array}$} & \multicolumn{3}{|c|}{$\begin{array}{l}\text { A. culicicola } \\
(n=16)\end{array}$} & \multirow{2}{*}{\begin{tabular}{|l}
$\begin{array}{l}\text { Total } \\
\%\end{array}$ \\
$\mathrm{R}$
\end{tabular}} \\
\hline & $\mathrm{R}$ & I & $S$ & $\mathrm{R}$ & 1 & $S$ & $\mathrm{R}$ & I & $S$ & $\mathrm{R}$ & I & $S$ & \\
\hline AMP & 100 & 0 & 0 & 93 & 0 & 7 & 96 & 0 & 4 & 100 & 0 & 0 & 94 \\
\hline CAR & 100 & 0 & 0 & 99 & 0 & 1 & 96 & 0 & 4 & 100 & 0 & 0 & 96 \\
\hline AML & 100 & 0 & 0 & 99 & 0 & 1 & 96 & 0 & 4 & 94 & 0 & 6 & 95 \\
\hline AMC & 33 & 5 & 62 & 9 & 13 & 78 & 11 & 31 & 42 & 25 & 1 & 74 & 15 \\
\hline TIC & 42 & 6 & 52 & 81 & 5 & 14 & 82 & 8 & 10 & 94 & 0 & 6 & 73 \\
\hline TIM & 2 & 2 & 96 & 15 & 11 & 74 & 33 & 17 & 50 & 50 & 0 & 50 & 22 \\
\hline PRL & 7 & 0 & 93 & 7 & 0 & 93 & 6 & 0 & 94 & 6 & 0 & 94 & 7 \\
\hline TZP & 5 & 0 & 95 & 1 & 0 & 99 & 3 & 0 & 97 & 0 & 0 & 100 & 3 \\
\hline KF & 88 & 0 & 12 & 37 & 5 & 58 & 10 & 0 & 90 & 6 & 0 & 94 & 32 \\
\hline FOX & 98 & 0 & 2 & 1 & 0 & 99 & 9 & 0 & 91 & 19 & 0 & 81 & 24 \\
\hline CRO & 0 & 0 & 100 & 0 & 0 & 100 & 7 & 0 & 93 & 31 & 0 & 69 & 5 \\
\hline CAZ & 0 & 0 & 100 & 1 & 0 & 99 & 5 & 0 & 95 & 19 & 0 & 81 & 4 \\
\hline CFP & 16 & 1 & 83 & 3 & 4 & 93 & 1 & 0 & 99 & 0 & 0 & 100 & 4 \\
\hline СтХ & 0 & 0 & 100 & 0 & 0 & 100 & 0 & 0 & 100 & 0 & 0 & 100 & 0 \\
\hline FEP & 0 & 0 & 100 & 0 & 0 & 100 & 0 & 0 & 100 & 0 & 0 & 100 & 0 \\
\hline ATM & 0 & 0 & 98 & 0 & 0 & 100 & 0 & 0 & 100 & 0 & 0 & 100 & 0 \\
\hline IMP & 2 & 0 & 98 & 0 & 0 & 100 & 1 & 0 & 99 & 0 & 0 & 100 & 1 \\
\hline CIP & 7 & 1 & 92 & 43 & 4 & 53 & 7 & 7 & 86 & 6 & 0 & 94 & 18 \\
\hline NOR & 7 & 0 & 93 & 34 & 0 & 66 & 7 & 0 & 93 & 13 & 0 & 87 & 16 \\
\hline TOB & 51 & 1 & 48 & 7 & 6 & 87 & 14 & 0 & 86 & 13 & 0 & 87 & 19 \\
\hline$A K$ & 16 & 0 & 84 & 3 & 0 & 97 & 4 & 6 & 90 & 6 & 0 & 94 & 6 \\
\hline $\mathrm{K}$ & 40 & 2 & 58 & 34 & 0 & 66 & 27 & 24 & 49 & 31 & 0 & 69 & 31 \\
\hline $\mathrm{CN}$ & 26 & 0 & 74 & 31 & 0 & 69 & 26 & 10 & 64 & 38 & 0 & 62 & 28 \\
\hline NET & 23 & 0 & 77 & 6 & 0 & 94 & 9 & 0 & 91 & 13 & 0 & 87 & 11 \\
\hline TE & 88 & 0 & 12 & 69 & 0 & 31 & 86 & 0 & 14 & 88 & 0 & 12 & 80 \\
\hline C & 14 & 0 & 86 & 25 & 0 & 75 & 5 & 0 & 95 & 6 & 0 & 94 & 13 \\
\hline$E$ & 93 & 0 & 7 & 96 & 0 & 4 & 85 & 7 & 8 & 81 & 0 & 19 & 88 \\
\hline SXT & 49 & 0 & 51 & 40 & 0 & 60 & 29 & 0 & 71 & 38 & 0 & 62 & 36 \\
\hline
\end{tabular}


rum. For this specie, regarding the $\beta$-lactams antibiotics, ampicillin, carbenicillin, amoxicillin, cephalothin and cefoxitin were less effective and of the aminoglycosides antibiotics the most effective was amikacin (84\%). Moreover, Aeromonas hydrophila showed values to quinolones (ciprofloxacin and norfloxacin) about $40 \%$ and on the other hand no significant difference in the values of resistance found in the remain species studied.

Identical susceptibility patterns to $\beta$-lactams antibiotics were found for the species of A. hydrophila, A. veronii, A. culicicola (Table 1), A. media, A. caviae and A. jandaei, with exception of cephalothin and cefoxitin that for these strains were more effective. Aeromonas isolates from different sources have been reported to have a relatively high resistance to $\beta$-lactams antibiotics, usually correlated with naturally occurring phenotypes of $\beta$-lactamases production [19]. The combination of aminopenicillin and carboxipenicillin with a $\beta$-lactamases inhibitor was effective in reducing resistance, as shown by the decrease in the proportion of resistant strains: 95\% (amoxicillin) versus 15\% (amoxicillin/clavulanic acid); $73 \%$ (ticarcillin) versus $22 \%$ (ticarcillin/clavulanic acid), that was more pronounced with amoxicillin. Nevertheless, these results are in agreement with the statement above, described in others studies [8], indicating that the penicillins resistance is probably due to the action of the inducible penicillinases susceptible to clavulanic acid.

The isolates found in this work from the species of A. hydrophila, A. veronii, $A$. culicicola were observed strains with sensitivity to aminopenicillins. The isolates from A. aquariorum, A. media, A. caviae and A. jandaei did not reveal sensitivity to any of these antibiotics. The results show that by using a culture media with ampicillin for the isolation of the genus Aeromonas, we may be underestimating the presence of these microorganisms from the different environments where they are found. Previous studies related to that Aeromonas strains are 100\% resistant to ampicillin, which is generally included in culture media for the isolation of aeromonads [20]; but this observation was based on studies using clinical isolates and it is possible that in a natural environment the selective constraints are different.

High resistance to first and second-generation cephalosporins (cephalothin and cefoxitin, respectively) has been detected in motile aeromonad isolates $[21,22]$ and are in accordance with our results for the strains of $A$. aquariorum measured in $88 \%$ and $98 \%$ of the isolates. Decreased susceptibility to third generation cephalosporins were previously reported [19]. A previous work [23] studied the presence of Aeromonas strains in mussels from the Adriatic Sea, reported isolates of $A$. hydrophila, A. caviae and A. bestiarium. These authors tested the activity of cephalosporins, first and third-generation (namely, cephalothin and cefotaxime). For cephalothin, we were obtained $100 \%$ of resistance in all species, which was in accordance with the results obtained in the present study in relation to the isolates of A. aquariorum, however, the values found for A. hydrophila were lower (37\% of resistance). Regarding the results for cefotaxime, the same authors report $4 \%$ of resistance to this antibiotic from isolates that belong to A. hydrophila.

Aztreonam, a monobactam antibiotic was effective against all species (two isolates resistant). Remarkably in this work, imipenem resistance was observed in three isolates of Aeromonas ( 1 A. aquariorum, 1 A. veronii and $1 \mathrm{~A}$. jandaei). Other studies also reported the incidence of strains resistant to this antibiotic [24,25]. Resistance to imipenem in non clinical strains supposed not subjected to selective pressure by use of such drug is a worrying trait as this is a last-resort antimicrobial agent used in the clinical environment. Chloramphenicol showed the highest efficacy against the bacterial strains tested (87\% sensitive and $13 \%$ resistant). Tetracycline resistance was $80 \%$ for Aeromonas spp. isolated, with no differences observed in these studied species. The resistance to tetracycline has been reported to be acquired and encoded by plasmids or transposons [26-28]. Ciprofloxacin and norfloxacin resistance was more prevalent among A. hydrophila isolates (43\% and 34\%, respectively) than the other species. Commonly, quinolones are synthetic antibiotics used as first therapeutic options for Aeromonas infections in humans $[29,30]$, also used in the treatment of bacterial fish diseases [31]. These drugs can persist for a long time in the environment, which could favor the emergence of resistant strains in environmental samples. The relatively high rates of resistance towards tetracycline and quinolones antibiotic might be due to extensive use of such compounds in hospital environments [30].

The results found for the aminoglycosides (gentamicin, kanamycin, tobramycin, amikacin and netilmicin) were observed, the differences between the susceptibility profiles of the A. aquariorum and of the others species. The antimicrobial agent with the most effective activity to Aeromonas spp. was amikacin ( $6 \%$ of resistance). The susceptibility tests with gentamicin and kanamycin revealed the highest percentages of resistance ( $28 \%$ and $31 \%$, respectively). Notably, $50 \%$ of the isolates of $A$. aquariorum showed resistance to tobramycin.

The trimethoprim/sulfamethoxazole susceptibility tests revealed a percentage of resistance $29 \%$ and $49 \%$ for the isolates in the present study (Table 1), with the lowest values found for $A$. veronii and the highest for A. aquariorum. The 3 isolates of $A$. media and one of $A$. jandaei revealed sensitivity to this antibiotic, while the isolate from $A$. caviae showed the resistance to trimethoprim/sulfamethoxazole. A previous work [25] on the characterization of Aeromonas spp. in samples of frozen fish reported a resistance for this antibiotic of $49 \%$, and the isolates from $A$. veronii presented $25 \%$ of resistance, that are similar to the values found in the present work.

A.salmonicida which is a known as fish pathogenic agent was not found in this study. This fact might suggest that this specie is not frequent in ornamental fish infections, as previously reported on South African ornamental fish [32]. Mesophilic aeromonads are considered to be opportunistic pathogens, capable of producing infections in weakened fish or as secondary invaders in fish populations suffering from others diseases $[15,33]$.

The present study revealed Aeromonas species are common inhabitants of aquatic ecosystems. Through genetic sequentiation were found 288 isolates that belong to 7 different species of this genus. There is a frequent occurrence and a considerable diversity of Aeromonas spp. in ornamental fish. All the isolates tested presented multi resistance to the used antibiotics. Some strains were resistant to all aminoglycosides tested. This was verified in 3\% (2 out of 67) of the isolates of A. hydrophila and $16 \%$ (7 out of 43 ) of A. aquariorum, collected from the water and skin. Also, there was a crossed multi resistance between aminoglycosides, quinolones, tetracycline, chloramphenicol, erythromycin and trimethoprim/sulfamethoxazole. The patterns of antibiotic resistance displayed by these organisms increase their potential health hazard and their broad distribution on different habitats is a problematic question. Therefore, these Aeromonas spp. strains showed to be potential reservoirs of antibiotic resistance genes, being of high importance to perform monitoring studies in order to evaluate and control its dissemination in aquatic environments. Thus ornamental fish can be considered a possible transmission route for aeromonads, however, further studies should be performed.

\section{Acknowledgment}

The authors acknowledge the financial support provided by the Portuguese 
Citation: Dias C, Mota V, Martinez-Murcia A, SaavedraMJ (2012) Antimicrobial Resistance Patterns of Aeromonas spp. Isolated from Ornamental Fish. J Aquacult Res Dev 3:131 doi:10.4172/2155-9546.1000131

Portuguese Foundation for Science and Technology (Carla Dias-SFRH/ BGCT/33354/2008) and strategic research project PEst-OE/AGR/ UI0772/2011)

\section{References}

1. Barker G (2001) Bacterial diseases. BSAVA manual of ornamental fish. Wildgoose WH (Ed), 185-194

2. Musa N, Wei SL, Shaharom F, Wee W (2008) Surveillance of bacteria species in diseased freshwater ornamental fish from aquarium shop. World Appl Sci J 3: 903-905.

3. Janda JM, Abbott SL (2010) The genus Aeromonas: taxonomy, pathogenicity, and infection. Clin Microbiol Rev 23: 35-73.

4. Martin-Carnahan A, Joseph S (2005) Genus I. Aeromonas. Bergey`s manual of systematic bacteriology, $556-578$

5. Yanez MA, Catalan V, Apraiz D, Figueras MJ, Martinez-Murcia AJ (2003) Phylogenetic analysis of members of the genus Aeromonas based on gyrB gene sequences. Int J Syst Evol Microbiol 53: 875-883.

6. Figueras MJ (2005) Clinical relevance of Aeromonas sM503. Rev Med Microbiol 16: 145-153

7. Beaz-Hidalgo R, Alperi A, Bujan N, Romalde JL, Figueras MJ (2010) Comparison of phenotypical and genetic identification of Aeromonas strains isolated from diseased fish. Syst Appl Microbiol 33: 149-153.

8. Saavedra MJ, Guedes-Novais S, Alves A, Rema P, Tacao M, et al. (2004) Resistance to beta-lactam antibiotics in Aeromonas hydrophila isolated from rainbow trout (Oncorhynchus mykiss). Int Microbiol 7: 207-211.

9. Kadlec K, von Czapiewski E, Kaspar H, Wallmann J, Michael GB, et al. (2011) Molecular basis of sulfonamide and trimethoprim resistance in fish-pathogenic Aeromonas isolates. Appl Environ Microbiol 77: 7147-7150.

10. Rowe-Magnus DA, Guerout AM, Mazel D (2002) Bacterial resistance evolution by recruitment of super-integron gene cassettes. Mol Microbiol 43: 1657-1669.

11. Schmidt AS, Bruun MS, Dalsgaard I, Pedersen K, Larsen JL (2000) Occurrence of antimicrobial resistance in fish-pathogenic and environmental bacteria associated with four Danish rainbow trout farms. Appl Environ Microbiol 66 4908-4915.

12. Jacobs L, Chenia HY (2007) Characterization of integrons and tetracycline resistance determinants in Aeromonas spp. isolated from South African aquaculture systems. Int J Food Microbiol 114: 295-306.

13. L'Abee-Lund TM, Sorum H (2001) Class 1 integrons mediate antibiotic resistance in the fish pathogen Aeromonas salmonicida worldwide. Microb Drug Resist 7: 263-272.

14. Schmidt AS, Bruun MS, Larsen JL, Dalsgaard I (2001) Characterization of class 1 integrons associated with R-plasmids in clinical Aeromonas salmonicida isolates from various geographical areas. J Antimicrob Chemother 47: 735-743.

15. Martinez-Murcia AJ, Saavedra MJ, Mota VR, Maier T, Stackebrandt E, et al. (2008) Aeromonas aquariorum sp. nov., isolated from aquaria of ornamental fish. Int J Syst Evol Microbiol 58: 1169-1175.

16. CLSI (2010) Performance standards for antimicrobial susceptibility testing. In: Information Supplement M100-S17. Clinical Laboratory and Standards Institute, Wayne, PA, USA, 76-79

17. Vila J, Ruiz J, Gallardo F, Vargas M, Soler L, et al. (2003) Aeromonas spp. and traveler's diarrhea: clinical features and antimicrobial resistance. Emerg Infect Dis 9: $552-555$.

18. Vivekanandhan G, Savithamani K, Hatha AA, Lakshmanaperumalsamy $P$ (2002) Antibiotic resistance of Aeromonas hydrophila isolated from marketed fish and prawn of South India. Int J Food Microbiol 76: 165-168.

19. Fosse T, Giraud-Morin C, Madinier I (2003) Phenotypes of beta-lactam resistance in the genus Aeromonas. Pathol Biol(Paris) 51: 290-296.

20. Radu S, Ahmad N, Ling FH, Reezal A (2003) Prevalence and resistance to antibiotics for Aeromonas species from retail fish in Malaysia. Int J Food Microbiol 81: $261-266$

21. Rall VLM, laria ST, Heidtmann S, Pimenta FC, Gamba RC, et al. (1998) Aeromonas species isolated from Pintado fish (Pseudoplatystoma sp): Virulence factors and drug susceptibility. Rev Microbiol 29.
22. Imziln B (2001) Occurrence and antibiotic resistance of mesophilic Aeromonas in three riverine freshwaters of Marrakech, Morocco. ScientificWorldJournal 1 : 796-807.

23. Ottaviani D, Santarelli S, Bacchiocchi S, Masini L, Ghittino C, et al. (2006) Occurrence and characterization of Aeromonas spp. in mussels from the Adriatic Sea. Food Microbiol 23: 418-422.

24. Morita K, Watanabe N, Kurata S, Kanamori M (1994) $\beta$-Lactam resistance of motile Aeromonas isolates from clinical and environmental sources. Antimicrob Agents Chemother 38: 353-355.

25. Castro-Escarpulli G, Figueras MJ, Aguilera-Arreola G, Soler L, Fernandez-Rendon E, et al. (2003) Characterisation of Aeromonas spp. isolated from frozen fish intended for human consumption in Mexico. Int J Food Microbiol 84: 41-49.

26. Rhodes G, Huys G, Swings J, Mcgann P, Hiney M, et al. (2000) Distribution of oxytetracycline resistance plasmids between Aeromonads in hospital and aquaculture environments: implication of Tn1721 in dissemination of the tetracycline resistance determinant Tet A. Appl Environ Microbiol 66: 3883-3890.

27. Miranda CD, Zemelman R (2002) Antimicrobial multiresistance in bacteria isolated from freshwater Chilean salmon farms. Sci Total Environ 293: 207-218.

28. Casas C, Anderson EC, Ojo KK, Keith I, Whelan D, et al. (2005) Characterization of pRAS1-like plasmids from atypical North American psychrophilic Aeromonas salmonicida. FEMS Microbiol Lett 242: 59-63.

29. Jones BL, Wilcox MH (1995) Aeromonas infections and their treatment. J Antimicrob Chemother 35: 453-461.

30. Alcaide E, Blasco MD, Esteve C (2010) Mechanisms of quinolone resistance in Aeromonas species isolated from humans, water and eels. Res Microbio 161: 40-45.

31. Giraud E, Blanc G, Bouju-Albert A, Weill FX, Donnay-Moreno C (2004) Mechanisms of quinolone resistance and clonal relationship among Aeromonas salmonicida strains isolated from reared fish with furunculosis. J Med Microbio 53: 895-901.

32. Mouton A, Basson L, Impson D (2001) Health status of ornamental freshwate fishes imported to South Africa: A pilot study. Aquarium Sciences and conservation 3: 313-319.

33. Camus AC, Durborow RM, Hemstreet WG, Thune RL, Hawke JP (1998) Aeromonas bacterial infections - motile aeromonad septicemia. Southern Regional Aquaculture Center (SRAC) Publication 478. 